\title{
Incidental detection of retained oil-based hysterosalpingography contrast medium with postoperative postpartum radiography: A case report
}

\author{
Harue Hayashida ${ }^{1}$, Kiichiro Furuya ${ }^{1}$, Hiroki Kurahashi ${ }^{1}$, Saya Yamashita ${ }^{1}$, Yangshil \\ Chang $^{1}$, Hiroaki Tsubouchi ${ }^{1}$, Kayoko Shikado ${ }^{1}$, and Kazuhide Ogita ${ }^{1}$ \\ ${ }^{1}$ Rinku General Medical Center
}

December 9, 2021

\begin{abstract}
Hysterosalpingography (HSG) is widely performed in combination with assisted reproductive technology, and the contrast medium used in this procedure may be retained in the pelvic cavity. In patients showing suspected operative-residue lesions after caesarean section, a medical history of HSG and details regarding abnormal findings can facilitate differential diagnosis.
\end{abstract}

\section{Hosted file}

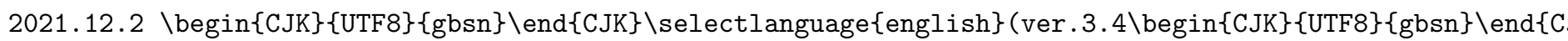
available at https://authorea.com/users/450457/articles/548751-incidental-detection-ofretained-oil-based-hysterosalpingography-contrast-medium-with-postoperative-postpartumradiography-a-case-report 
Figure 1.
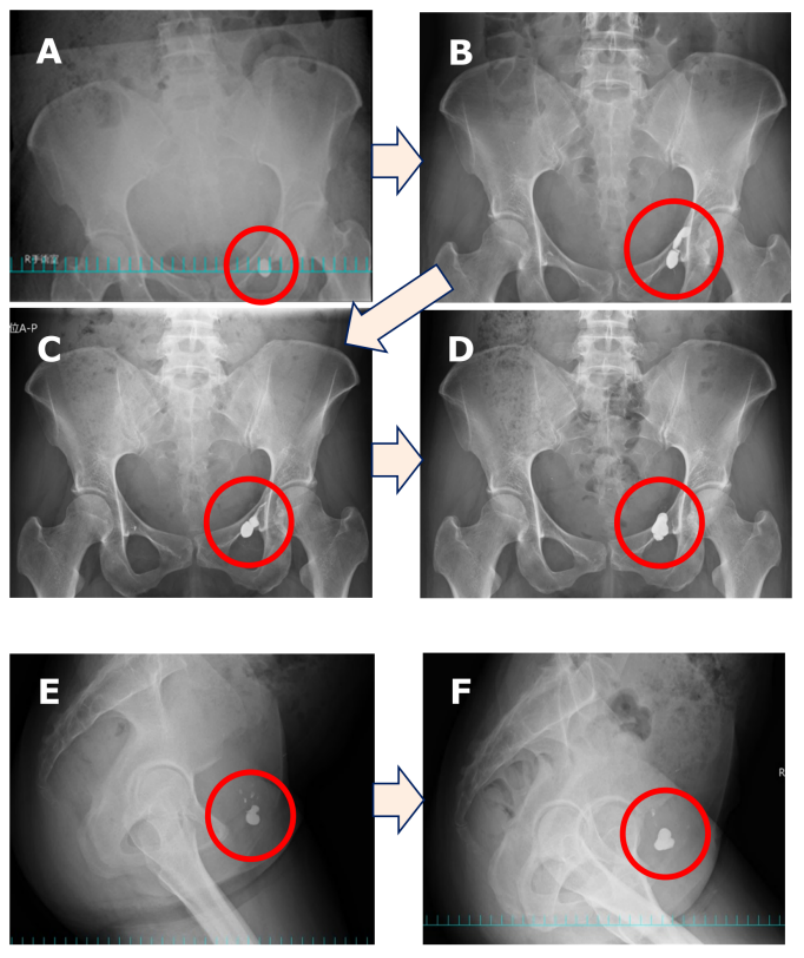
Figure 2.

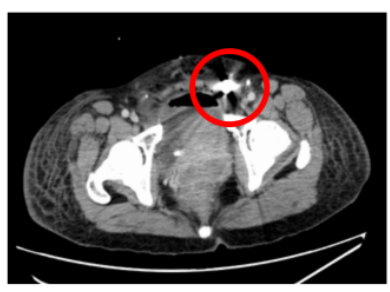




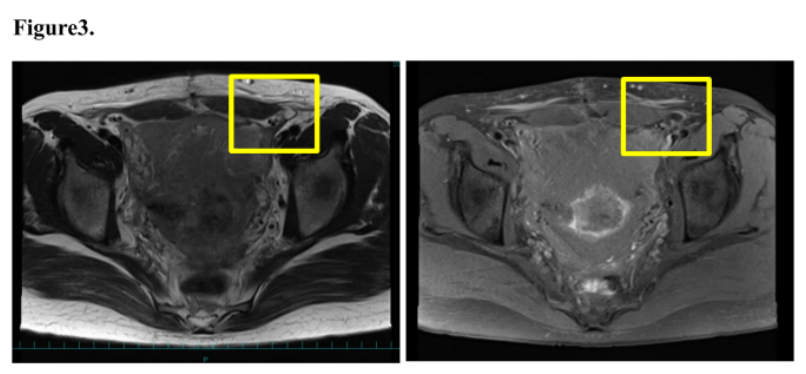

